\title{
CIBERDEMOCRACIA: UM CONCEITO LIBERAL
}

\section{CYBERDEMOCRACY: A LIBERAL CONCEPT}

\author{
Silvia Ramos Bezerra*
}

\section{RESUMO}

O objetivo desta pesquisa é apresentar o conceito de ciberdemocracia como uma terminologia própria do paradigma político da teoria liberal. Por meio da retomada do contexto histórico de desenvolvimento dos estudos sobre Internet, pretendemos demonstrar como a ciberdemocracia é uma definição que se origina e se difunde como parte de uma leitura cívico-liberal sobre as relações entre Internet e Política. Neste sentido, pois, afirmar a incapacidade desta interpretação de explicar os movimentos sócio-políticos ocorridos nos últimos anos pelo mundo que se alicerçam nas ferramentas de comunicação providas pela Internet e que têm um caráter eminentemente autogestionário, não-institucional e anticapitalista.

Palavras-chave: Internet, Ciberdemocracia, Liberalismo.

\begin{abstract}
The aim of this research is to present the concept of cyberdemocracy as a specific terminology of the liberal theorypolitical paradigm. Taking into consideration the historical context of the development of studies about the Internet, we intend to demonstrate how cyberdemocracy is a concept that originates and spreads as part of a civic-liberal reading of the relationship between the Internet and politics. Therefore, it is possible to affirm the incapacity of this interpretation to explain the socio-political movements that took place in recent years around the world that are grounded on communication tools provided by the Internet that have above all a self-managed, non-institutional and anti-capitalist character.
\end{abstract}

Keywords: Internet, Cyberdemocracy, Liberalism.

*Doutoranda em Ciências da Comunicação pela Escola de Comunicações e Artes da Universidade de São Paulo 


\section{Notas introdutórias: pesquisa administrativa versus teoria crítica}

Nos anos 1990, com a expansão da Internet e sua incorporação nos espaços sociais, inicia-se um processo de interpretação dos papéis desempenhados pelas ferramentas de conexão na política. Estas pesquisas pioneiras sobre o tema fizeram parte de um contexto histórico particular: a efetivação das premissas do neoliberalismo econômico e da globalização.

Neste cenário, surgem os chamados internet studies, denominados também por pesquisa de Internet, TIC e da sociedade, informática social, informática e sociedade, nova pesquisa de mídia, teoria da sociedade da informação, estudos sobre sociedade da informação, pesquisa na Web, entre outros. Qualquer que seja a denominação escolhida, observa-se que as pesquisa que versam sobre a Internet como novo meio de comunicação, assim como as pesquisas sobre mass media realizados durante todo o século XX, podem ser agrupadas em duas tendências principais, que são opostas: a pesquisa administrativa e a teoria crítica.

As pesquisas administrativas no campo da Comunicação, em geral de origem anglófona, prevaleceram vigentes até o final dos anos 60, principalmente nos Estados Unidos. Denominada também mass communication research, este modelo de pesquisa tem diferentes características que muitas vezes se sobrepõe na composição da forma de abordagem do fenômeno comunicacional. Porém quatro características lhe dão certa unidade:

a orientação empirista, tendente a enfoques quantitativos; a orientação pragmática, mais política do que científica (voltada para demandas do Estado e por ele instrumentalizada); a ênfase na comunicação midiática como objeto de estudo; e a inspiração em modelos matemáticos, funcionalistas e automatistas (HOHLFELDT, 2001, p. 120-130).

Já a teoria crítica, de origem predominantemente europeia, se desenvolveu a partir dos estudos sobre produção cultural, racionalidade instrumental e expansão do sistema capitalista. Pois,

(...) paralelo ao desenvolvimento da pesquisa norte-americana, outras correntes de pensamento surgiram também na Europa, com fundamentos e perspectivas completamente distintas da communication research. Entre elas, destacase a Escola de Frankfurt, tradição de pesquisa iniciada nas primeiras décadas do século XX, fundamentalmente a partir da elaboração crítica de pensadores como Theodor W. Adorno; Walter Benjamin; Herbert Marcuse e Max Horkheimer (BOTELHO, 2004).

No campo da Comunicação, a teoria critica pressupõe uma metodologia de pesquisa que consegue ser ao mesmo tempo cientificamente orientada, mas que funciona também como elemento de práxis política. Como afirma Ronaldo Botelho (2004): “em linhas gerais, era a [proposta] de fundir o comportamento crítico com a proposta política, de modo a superar a crise da razão".

Desta forma, o ponto de partida da reflexão dos pensadores da chamada teoria crítica é, sem dúvida, a teoria social de Karl Marx. Fuchs e Mosco (2012) ressaltam a herança marxiana de uma práxis emancipadora na teoria crítica dedicada à Comunicação, pois "se alguém quiser estudar criticamente comunicação e utilizar a pesquisa para a mudança social, então a obra de Marx fornece elementos essenciais" (p.129, tradução nossa).

É o que também afirma Deepa Kumar ao tratar da atualidade do pensamento de Marx para as pesquisas em Comunicação.

O materialismo dialético, método de análise desenvolvido por Marx e Engels, é mais relevante para o conhecimento nos estudos de mídia e cultura hoje por pelo menos duas razões: a crise do neoliberalismo e o colapso do stalinismo (KUMAR, 2009, p. 154).

Como modelo teórico, a pesquisa administrativa foi mitigando gradativamente sua área de influência. Isso ocorreu devido ao fato de que as abordagens previam o processo comunicacional de modo mecânico e pouco complexo, por isso insuficientes para pensar a nova realidade da expansão da influência dos meios de comunicação nas sociedades pelo mundo. Desta forma, “(...) a partir dos anos 70 a pesquisa administrativa em comunicação começa a assumir contornos mais complexos e interdisciplinares, inclusive por influências da própria teoria crítica" (BOTELHO, 2004). 


\section{Estudos sobre Internet: a prevalência da pesquisa administrativa}

Apesar da expansão da teoria crítica nos estudos sobre mídia durante o século XX (influenciando o surgimento de outras abordagens como a dos Estudos Culturais, da Semiótica, do Pós-estruturalismo, da Economia Política da Comunicação e da Critical Communication Studies) surpreendentemente, foram os métodos de análise da pesquisa administrativa, um modelo teórico já em ocaso no resto do mundo, que prevaleceu nos primeiros estudos sobre Internet nos anos 1990 nos Estados Unidos, uma vez que:

(...) a pesquisa administrativa ainda tem bastante penetração nos círculos de estudos sobre mídia nos Estados Unidos, daí a importância da retomada das leituras da obra de Marx para o enfrentamento destas teorias que são aliadas aos projetos políticos e culturais de conglomerados de mídia em franca expansão pelo mundo, ensejados pelas novas tecnologias da comunicação (BEZERRA, 2009, p. 153).

A prevalência da pesquisa administrativa nos estudos sobre Internet ocasionou determinadas características a serem observadas nestas investigações iniciais: a primeira, a aplicação do método empirista, de natureza quantitativa; a segunda, a forte orientação mercadológica e estatal na condução das pesquisas; a terceira, o viés pragmático que orientou o processo de produção de resultados; a última característica, o uso sistemático de modelos matemáticos de investigação.

Para que possamos compreender como as primeiras pesquisas sobre Internet foram afetadas por estes métodos de abordagem, recorremos à historiografia dos estudos sobre Internet proposta por Wellman (2011). De acordo com o autor, podemos dividir em três momentos distintos o processo de desenvolvimento dos estudos de Internet.

$\mathrm{O}$ que ele denomina como a primeira era dos internet studies se revelou com uma fase de intenso entusiasmo com as novas tecnologias de conexão. As análises eram quase sempre opinativas e a pesquisa empírica escassa. Neste momento, os autores assumiam uma perspectiva a-histórica ao desligar as potencialidades das tecnologias emergentes de seu contexto de criação e da sociedade em que surgiram.

Com isso, as análises ou eram utópicas (os prometeicos) ou distópicas (os fáusticos), já que as novas "descobertas" da informática teriam o condão de transformar para melhor ou pior a realidade social no mundo.

As análises foram muitas vezes utópicas: exaltar a Internet como igualitária e global, e ignorando diferenças de poder e status que poderiam afetar as interações on e offline. Os distópicos também tinham algo a dizer: preocupar-se de que "enquanto tudo isso razzle-dazzle nos conecta eletronicamente, nos desconecta uns dos outros, ter 'interface' mais com computadores e telas de TV do que olhar na cara dos nossos companheiros seres humanos" (WELLMAN APUD FOX, 1995, p.12, tradução nossa).

A segunda era dos estudos da Internet se inicia em 1998 como um retorno das investigações baseadas no trabalho empírico. Utopias e distopias começam a arrefecer, mas a força econômica do novo meio vai influenciar decisivamente o processo de produção de conhecimento científico sobre impactos sociais da rede.

A segunda idade de estudos Internet foi dedicada a documentar essa proliferação de usuários da Internet e usos. Foi com base em pesquisas de grande escala, originalmente feito por empresas orientadas para marketing (e com alguma tendência para exagerar sua utilização), mas cada vez mais feito pelos governos, acadêmicos e empresas a longo prazo (WELLMAN, 2011, p. 19-20, tradução nossa).

Para Wellman (2011), as duas fases iniciais mantém o aspecto de euforia da "descoberta" da rede: a primeira fase, até 1998, com os pesquisadores ainda fortemente impactados pelas possibilidades das tecnologias que estavam sendo disponibilizadas; e a segunda, pós-1998, quando a Internet foi vislumbrada como veículo de produção de mercadorias e serviços altamente lucrativos.

No atual estágio, a chamada terceira era, os estudos centram-se em conceber a Internet em seu caráter de "utilidade para as massas". Com as novas tecnologias de comunicação incorporadas à vida cotidiana, graças à expansão do acesso e à migração pra outras plataformas, como celulares e tablets, a Internet deixa ser considerada como um advento proeminente e passa ser vista como parte importante da socialização humana. Neste momento, segundo Wellman (2011), os estudos passam a entender que a Internet de modo mais nuançado e sofisticado. Esta 
nova interpretação é mais condizente com a diversidade de fatores que transformam a Internet num fenômeno social complexo.

Esta mesma realidade detectada nos estudos voltados à investigar a Internet como fenômeno comunicacional pode ser também transposta para o universo das pesquisas que relacionam Internet e Política. É o que se conclui pelos resultados discutidos por Chadwick e Howard em Routledge Handbook of Internet Politics (2009).

Neste texto Chadwick e Howard apresentam um estudo que investiga, entre os anos de 1995 a 2006, por meio do método booleano simples, a presença de termos relacionados com Internet e Política em títulos, resumos ou palavras-chave de indexação num dos mais importantes banco de dados de artigos acadêmicos da web pelo mundo: o ISI web of science index.

Os resultados obtidos apontam o crescimento das pesquisas nesta temática que inclusive superaram a publicação de artigos científicos que pensavam a Política nos meios de comunicação de massa já consolidados, como vemos no gráfico abaixo.

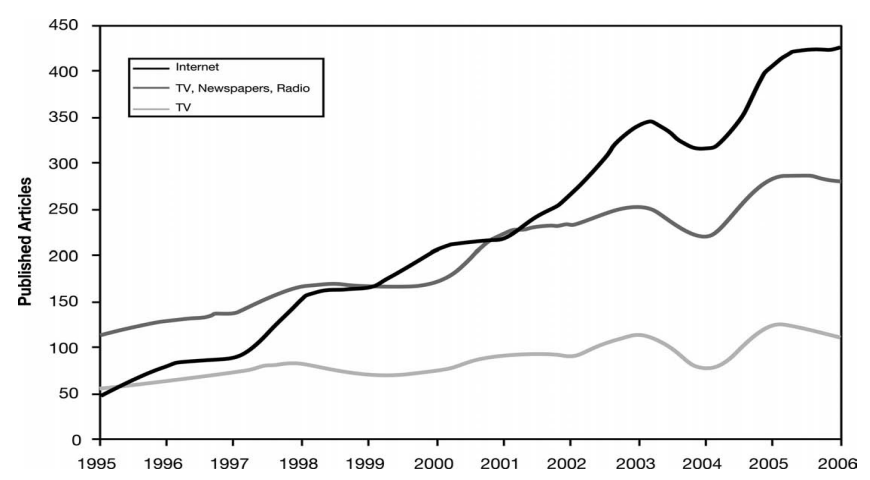

Artigos acadêmicos publicados sobre Comunicação e Política, 1995- 2006.

Fonte: (CHADWICK, HOWARD, 2009, p. 01).

Legenda: TS $=\left(\right.$ Internet OR web) AND TS $=\left(\right.$ politic $^{\star}$ OR govern $\left.^{\star}\right) ; \mathrm{TS}=\left(\right.$ television OR newspaper ${ }^{\star} \mathrm{OR}$ radio $)$ AND TS $=\left(\right.$ politic $^{\star}$ OR govern $\left.{ }^{\star}\right) ;$ TS $=($ television $)$ AND TS $=\left(\right.$ politic $^{\star}$ OR govern $\left.{ }^{\star}\right)$ in ISI Web of Science scholarly article database 1995-2006.

Apesar da importância destes dados levantados, como admitem seus autores, os resultados não abrangem todo o universo da produção científica como livros, capítulos de livros, relatórios, papers e apresentações de conferências (CHADWICK; HOWARD, 2009, p. 01, tradução nossa).
Se levarmos em conta a periodização proposta por Wellman, é na segunda fase dos internet studies (principamente pós-1998) que emergem os estudos principais sobre as relações entre Internet e Política. Nesta etapa, sem dúvida, registra-se o aparecimento das pesquisas desta temática e seu exponencial crescimento.

\section{Apesar disso,}

(...) muitos comentaristas ficaram intrigados com a capacidade do novo meio para auto-expressão e seu potencial para interferir nas relações sociais, políticas e econômicas, mas havia um palpável "vamos esperar para ver" no discurso acadêmico de meados dos anos 1990. Alguns estudiosos descartaram este domínio de investigação, aparentemente sem efeito sobre as evidências tradicionais da ciência política, como gastos de campanha, o número de eleitores e formação de opinião pública (CHADWICK; HOWARD, 2009, p. 03, tradução nossa).

Nesta etapa, a Internet como ferramenta comunicativa para a política ainda fora interpretada no universo acadêmico como uma variante com pouco impacto sobre o cenário político-eleitoral. O que se observa da produção científica do período é que a política praticada na rede era "politics as usual", para usar a expressão americana.

Isso significa dizer que os estudos acadêmicos mais relevantes sobre Política e Internet da última década do século XX, em sua maioria, partiram de um modo particular de compreender o que é a política, práxis e de sua natureza no contexto socioeconômico, influenciando de maneira decisiva a elaboração teórico-cientifica destes anos.

De fato, há mais de quinze anos se investigam ferramentas (fóruns, listas de discussão, principalmente) e iniciativas (sistemas de fóruns eletrônicos baseados na internet para deliberação pública sobre problemas locais e nacionais, por exemplo) dedicadas à discussão política online para se verificar se e até que ponto nelas se cumprem os requisitos fundamentais, seja da esfera pública, seja de uma deliberação normativamente fundada (GOMES, 2011, p. 22). 


\section{Ciberdemocracia e o paradigma cívico- liberal}

As abordagens promovidas nas investigações sobre Internet durante a década de 1990, já aludidas, permitem-nos afirmar que sempre houve uma orientação político-teórica no processo de condução das pesquisas. Isto significa pensarmos que o próprio sentido de política, que vai impactar na maneira de compreender o uso político da Internet, norteou substancialmente o procedimento de análise e de entendimento do novo meio em expansão.

Neste sentido, convém afirmarmos que foi o paradigma político cívico-liberal que sempre prevaleceu nestas abordagens, e além disso, compreender que nestes estudos a política foi tomada de um modo bastante institucionalizado e pelo ponto de vista estrito da cidadania democrática-eleitoral.

Assim, observa-se que o velho paradigma sócio-político liberal foi o principal modo de orientação para compreender um fenômeno inteiramente novo e original, qual seja, a relação Internet-Política. Esta contradição encontramos na reflexão proposta por Mossberger, Tolbert e McNEAL (2008):

(...) o engajamento cívico está no coração da virtude republicana, pois oferece as bases para a participação política de longo prazo. Há debates importantes sobre os efeitos da Internet sobre engajamento cívico e "capital social", ou a capacidade de participar como membro da comunidade política maior. Muitos destas controvérsias se baseiam nas descobertas preliminares, durante uma fase precoce do desenvolvimento da Internet (2008, p. 47-48, tradução nossa).

A isso se soma o fato de que a Internet era compreendida como mais um dentre outros meios de comunicação de massa, o que justificaria afirmar ser esta um meio eminentemente republicano. É o que enfatizam os autores de Digital Citizenship:

(...) historicamente, a inovação em tecnologia de telecomunicações gerou especulações sobre como isso afetaria a participação democrática. Os valores do republicanismo cívico têm há muito colorido os debates sobre o mérito público das tecnologias que promovam novas formas de comunicação de massa, como o rádio e a televisão. Estamos numa tal encruzilhada com a Internet (MOSSBERGER; TOLBERT; McNEAL, 2008, p. 69, tradução nossa).
Alguns autores influenciados por esta perspectiva, principalmente, nas pesquisas promovidas nos Estados Unidos, destacaram a importância da Internet como instrumento de reforço do republicanismo cívico e o liberalismo americano.

Mais recentes propostas para a democracia participativa ou "forte" que mesclam os valores republicanos de virtude cívica com normas liberais defendem a igualdade política (Barber, 1984; Bowler; Donovan; Tolbert, 1998). Para se estender essa tecnologia da informação para reforçar a capacidade de informação e mobilizar participações cívicas pode-se defender as tradições republicanas de cidadania (MOSSBERGER; TOLBERT; McNEAL, 2008, p. 06, tradução nossa).

Tais estudos, ainda que de modo preliminar e com os poucos recursos tecnológicos de investigação da audiência da Internet disponíveis, chegaram a afirmar por meio de estatísticas de acesso, as inclinações políticas majoritárias dos indivíduos que acessarem a rede mundial de computadores ainda nos anos 1990. Com base nestes resultados, Shenk chegou a afirmar que "o ciberespaço é republicano" (1997, p.174, tradução nossa).

As leituras republicanas e cívico-liberais presentes nestes internet studies determinaram que a rede fosse compreendida apenas por seu viés institucional, já que o engajamento cívico propalado convencionava a participação política ao limite estrito daquilo que as instituições conferiam de abertura deliberativa.

Justamente esta forma de abordagem, que como vimos é herdeira das proposições dos anos 1930 da pesquisa administrativa, fortemente enraizada no liberalismo econômico norte-americano, vai desembocar numa perspectiva de análise que pressupõe o sistema democrático representativo como única forma política a ser fomentada pelo desenvolvimento da Internet.

Baseado nesta premissa, os internet studies desenvolveram o conceito de cyberdemocracy, como o corolário deste republicanismo cívico e do suposto nascimento de uma cidadania digital.

Em grande parte destas primeiras pesquisas, toda a forma de práxis política praticada na rede mundial de computadores foi compreendida de modo institucionalizado, formalista e fortemente estruturado nas determinações de Estados e Mercados. 
Em decorrência disto, para dar conta de responder conceitualmente como seriam as facilitações que os instrumentos de rede poderiam produzir na participação política orientada institucionalmente, uma terminologia bastante imprecisa começou a ser formulada nestes estudos.

Termos como democracia virtual (SNIDER, 1994; HACKER; VAN DIJK, 2000), democracia digital (HAGGEN, 1995), democracia plug and play (GOMES, 2009), ciberdemocracia, entre outros, aparecem para fornecer uma resposta conceitual ao que seria esta nova prática política no contexto das tecnologias da comunicação e informação. Para além destes significados iniciais, é preciso enfatizar o que estas definições parecem guardar de caráter comum: o fato de que sustentam uma mudança de paradigma no sentido da política estatal (eleitoral) com o surgimento da rede.

Durante fins do século XX, cientistas políticos e pensadores sociais têm apontado as fundamentais transformações na participação democrática pelo globo, que indicam um enfraquecimento do modelo de democracia representativa. Como perceberam alguns autores (DALTON, 2004; PUTNAM, 2000; BEST; KRUEGER, 2005; MARQUES, 2008), houve uma redução do grau de interesse em temas relacionados à política partidária, de comparecimento nos pleitos eleitorais e mesmo de confiança no sistema democrático.

Se muitas causas podem ser apontadas como determinantes neste estado de coisas, o que de fato pode-se com certeza afirmar é que a democracia representativa tem apresentado diversos limites.

Nos últimos [anos] o regime democrático liberal está vivendo uma profunda crise de legitimidade e consenso popular. Apesar do grande sucesso que o regime democrático liberal ainda obtém entre as instituições e os partidos políticos, percebe-se uma preocupante desafeição por parte do cidadão comum, diminuindo sensivelmente o número de votantes e as filiações partidárias, espalhando-se um sentimento de desconfiança pela classe política na sua totalidade, independentemente da posição ideológica defendida. O bem-estar do capital se tornou a principal referência das democracias contemporâneas, que, descumprindo todas as promessas de liberdade, igualdade e fraternidade, legitimaram o desmantelamento das conquistas sociais, a reconfiguração dos direitos trabalhistas, a privatização do bem público e a "publicização" do bem privado (GIACOBBO SCAVO; BEZERRA, 2014)

É diante deste contexto que a Internet significou, como acreditaram os pensadores liberais, uma esperança de melhoria dos processos democráticos e sua defesa perante o descrédito que sofreu nas últimas décadas pelo mundo (JENNINGS; ZEITNER, 2003; OWEN; VIDERAS; WILLEMSEN, 2008).

Este entusiasmo democrata com novos meios de comunicação não é manifestação recente. Em meados do século XX, com a expansão da televisão, surge a terminologia democracia eletrônica que "é um conceito com uma história relativamente longa. Tem sido uma característica central das utopias tecnológicas propostas por acadêmicos, políticos e ativistas desde a década de 1960" (TSAGAROUSIANOU, 1998, p. 01, tradução nossa).

Neste sentido, a anteriormente denominada $e$ -democracia ou democracia eletrônica, (a partir da junção das palavras eletrônica e democracia), passou a também ser usada para pensar a Internet e a prática política de governos e instituições. Sua genealogia, portanto, remonta o desenvolvimento das mídias eletrônicas do século XX, principalmente da televisão.

Se a designação e-democracia coloca a Internet em igualdade com outros meios de comunicação, a terminologia ciberdemocracia (OGDEN, 1994; POSTER, 1995) pretende justamente discutir a prática política especificamente no cenário da rede mundial de computadores e das novas tecnologias de conexão. $\mathrm{O}$ fato é que o advento da computação em rede ampliou sobremaneira as proposições da e-democracia, oferecendo novos canais de acesso à informação política local e permitindo uma maior participação na tomada de decisões, como a criação das cidades digitais.

É preciso esclarecer que a ciberdemocracia significa o uso de tecnologias e estratégias de informação e comunicação pelos diversos atores sociais (sejam governos, políticos eleitos, meios de comunicação ou organizações políticas, movimentos sociais, cidadãos e eleitores), nos processos políticos e de governança das nações e das comunidades locais.

Para Levy (2005), os primeiros passos da cibedemocracia são resultado do desenvolvimento no ciberespaço de práticas políticas novas, com fulcro nas 
comunidades locais em rede. Mais do que a sujeição das populações, o estilo proveniente da democracia eletrônica reforça a capacidade de ação administrativa dos cidadãos, pois "as novas ágoras on line permitem que novos modos de informação e deliberação política venham à luz" (LEVY, 2005, p. 367).

Como também enfatiza Lopes e Freire: "a ciberdemocracia encontra-se, no maior acesso à informação governamental e a interação entre o Estado e sociedade civil, através dos meios eletrônicos" (2010, p. 03).

Além disso, a interação possibilitada no paradigma da ciberdemocracia pode ser: prestação de informação unidirecional, comandada pelos governos e instituições; o segundo tipo, uma relação de mão dupla, onde os cidadãos têm a oportunidade de dar feedback sobre as questões; e, finalmente, uma relação de parceria em que cidadãos estão ativamente engajados na formulação de políticas ${ }^{1}$.

Apesar disso, a efetividade dos paradigmas de uma ciberdemocracia passa pela ideia de que os cidadãos não só contribuem para o governo com críticas ou sugestões, mas que, coletivamente, podem trabalhar para melhoria de suas próprias comunidades locais. Assim, na ciberdemocracia, este modo de ação cívica quase sempre assume a forma de ingresso e uso ativo dos indíviduos nas redes sociais e organização/participação em fóruns online. No Brasil, isto tem sido observado na explosão dos debates sobre pautas legislativas nas redes sociais, como Facebook ou Twitter.

Assim, a aplicabilidade das metas propostas no debate sobre a ciberdemocracia requer interesse governamental em fornecer ou facilitar os fóruns de debate público e a real participação cidadã nas deliberações depende muito mais de uma "vontade política" do que necessariamente do cidadão em congregar. Cabe, pois, ao governo disponibilizar ou não este diálogo, o que, muitas vezes, depende de fatores políticos-econômicos sempre externos às tecnologias e suas possibilidades.

Diante das ferramentas comunicacionais diversos limites técnicos foram ultrapassados, mas a disponibilização e o efetivo emprego das tecnologias no processo decisório ainda depende fundamentalmente do poder estatal.
A "ciberdemocracia" poderia ser experimentada e outras formas de participação e mecanismos representativos poderiam ser propostos. Atualmente é muito fácil organizar consultas rápidas à população sobre temas de interesse imediato e que requeiram um pronunciamento de relativa urgência. Plebiscitos e referendos não teriam porque serem casos excepcionais na vida social e política. Ao menos tecnologicamente já não há mais desculpas (CRUZ, 2009, p. 13).

Para Haggen (1997), duas variantes da ciberdemocracia têm sido desenvolvidas: a primeira delas, certamente mais conservadora e liberal, salienta a importância do mercado livre e do sistema capitalista para ampliação da democracia; e a segunda, mais libertária, salienta a importância da valorização dos anseios comunitários. Desta mesma forma, também são estes dois paradigma teórico-políticos que orientam os estudos sobre as potencialidades políticas da ciberdemocracia.

Neste sentido, três tendências políticas podem ser identificadas nos estudos sobre Internet e Política: o individualismo liberal, quando a Internet propicia práticas políticas que corroboram para a expressão de interesses individuais; o comunitarismo, onde a rede auxilia na construção de modelos democráticos calcados em valores coletivistas; e a democracia deliberativa, "um modelo democrático é legitimado por sua facilitação do discurso racional na esfera pública. [Pois] todas as três posições podem ser identificadas dentro da prática e retórica na democracia-internet" (DAHLBERG, 2001, p. 158, tradução nossa).

Contudo, é possível observar que o paradigma liberal tem prevalecido tantos nos estudos sobre o tema como nas práticas governamentais, uma vez que estes tem como base valores e práticas da democracia representativa liberal. Além disso, os diversos aspectos dos modelos de ciberdemocracia também podem variar de acordo com o tipo de regime politico vivenciados nos países. Isto significa dizer que uma única plataforma de interação em rede pode comportar diferentes pontos de vista políticos.

É o que afirma Kaczmarczyk (2010, p.1400, tradução nossa) no esquema a seguir: 


\begin{tabular}{|l|l|c|c|}
\hline \multicolumn{4}{|c|}{ Os principais aspectos dos modelos de e-democracia } \\
\hline & Democracia Fina & Democracia Forte & Democracia Breve \\
\hline Objetivo & Eficiência escolha & Consenso & Poder do povo \\
\hline Solo de legitimidade & Prestação de contas & Debate público & Princípio da maioria \\
\hline Papel do cidadão & Consumidor & Formador de opinião & Tomador de decisão \\
\hline Mandato de eleição & Aberto e interativo & $\begin{array}{c}\text { Ligado nas tecnologias } \\
\text { de comunicação e uso } \\
\text { focado destas }\end{array}$ & Informação e Discussão \\
\hline
\end{tabular}

Na prática, é preciso destacar que, na maioria dos países, os modelos de ciberdemocracia não têm alcançando resultados esperados, principalmente em termos de democratização das decisões e abertura participativa, evidenciando que a realidade sempre esteve aquém das previsões futuristas sobre Internet.

Apesar da existência de um enfoque comunitário, o modo conservador de interpretação prevaleceu nos estudos anglosaxônicos sobre Internet; situando o horizonte da práxis política dentro da afirmação dos limites da participação democrática moldada pelo Estado. É o que observa Bigliazzi:

(...) o que nos interessa no que concerne à ciberdemocracia é o fortalecimento da relação entre o Estado e o Cidadão, visto que o princípio basilar da ciberdemocracia está na possibilidade de ampliar, significativamente, a participação popular efetiva nas decisões governamentais (BIGLIAZZI GARCIA, 2008).

\section{Os limites da ciberdemocracia: considerações finais}

A proposta contida no conceito de ciberdemocracia tem como característica fundamental formular a questão do uso político da Internet sempre do ponto de vista do engajamento cívico. Estas reflexões limitam a mensuração do uso político da rede à esfera do consumo de serviços prestados por instituições governamentais, mitigando a importância da ação direta e da participação ativista.

Deste modo, ao se limitar o sentido social do uso político da Internet as postulações do paradigma cívico liberal, consubistanciado no conceito de ciberdemocracia, perde-se de vista os indicadores que têm apontado para uma utilização mais ampla, ativa e direta das ferramentas disponibilizadas pela rede.
Diferentemente das previsões dos pensadores da ciberdemocracia, a comunicação móvel promovida por celulares, os aplicativos e as redes sociais têm permitido a construção de um tipo de ativismo nãoinstitucionalizado e muito mais contestador do que se espera nos cânones da cidadania republicana-liberal.

Os eventos políticos ocorridos no mundo nos últimos anos (protestos contra a crise nos países europeus, as ocupações ocorridas nos Estados Unidos contra a desigualdade promovida pelo sistema capitalista, as batalhas para derrubada de regimes ditaroriais e por direitos humanos no Oriente Médio, as manifestações por serviços públicos e contra a corrupção no Brasil e as lutas trabalhistas recentes na China, entre outras) demonstraram que a articulação política de coletivos e movimentos sociais não permaneceu restrita ao horizonte da participação eleitoral, produzindo um debate intenso para formulação de projetos de democracia direita, anticapitalista e de construção de outros modelos de sociedade.

Os desafios evidenciados nestes eventos políticos recentes pode nos levar a compreender que os limites auto-impostos desta forma de pensar o papel da rede na política impediu (e ainda tem impedido) que os internet studies avancem na compreensão do verdadeiro caráter emancipatório contido na Internet.

Isto acontece seja porque este caráter não consiga ser desvelado pelo modelo da pesquisa administrativa que tem conduzido estas investigações, como vimos, seja porque esta percepção não seja politicamente conveniente (vide os recentes enfrentamentos de ciberativistas que atuam em pautas políticas contra seus governos, tanto em regimes fechados, como é o caso da China e países do Oriente Médio, como em democracias tradicionais, como é o caso dos Estados Unidos).

É neste sentido que observamos que as fragilidades, incongruências e insucessos que 
as práticas políticas ciberdemocráticas têm se defrontando até o momento, demonstram porque as proposições da ciberdemocracia esbarram não somente nas deficiências técnicas, mas principalmente em suas determinações teóricopolíticas mais profundas.

O paradigma cívico liberal de interpretação das potencialidades políticas da Internet sustentava cânones científicos e uma visão política muito específica que conduziu a análise para uma compreensão sempre institucionalizada da rede, sem que pudesse vislumbrar que na práxis política da Internet sempre estiveram presentes elementos de crítica ao capitalismo, ao Estado e as suas relações, como evocam insistentemente as vozes, cartazes, posts e mensagens divulgadas nos protestos internacionais dos últimos anos.

Neste sentido, acreditamos que os desafios impostos por este novo fenômeno sociopolítico impõe retomarmos as postulações da teoria crítica no campo da Comunicação que, certamente, pode nos fornecer instrumentos de análise mais favoráveis, na medida de sua adaptação conceitual e metodológica à realidade que se descortina.

\section{Referências}

BEST, S. J. KRUEGER, B. S Analyzing the representativeness of internet political participation. Political Behavior, vol. 27 , no. 2, 2005, p. 183-216.

BEZERRA, S. B. Marxismo e Comunicação Social. Revista Sinal de Menos, Ano 1, n³, 2009, p.152-153. Disponível em: https://dl.dropboxuser content.com/u/65249844/ BEZERRA_Silvia_Marxismo_e_comunicacao_social.pdf. Acesso em: 24 mar.2014.

BIGLIAZZI GARCIA,T. H. A Democracia na Era do Governo Eletrônico. 2008. Disponível em: http:/www. ciberetica.org.br/ trabalhos/anais/ 27-64-c1-8.pdf>. Acesso em: 03 jul. 2014.

BOtelho, R. M. Pesquisa administrativa X Teorias críticas: Contrastes entre duas tendências. 2004. Disponível em: http://bocc.ubi.pt/pag/botelho-ronaldo-duasteorias.html. Acesso em: 30 jan. 2013

CHADWICK, A. HOWARD, P.N. Routledge Handbook of Internet Politics. New York: Routledge, 2009.

CRUZ, P. M. Ensaio sobre a necessidade de uma teoria para a superação democrática do estado constitucional moderno. 2009. Disponível em: http://www.conpedi.org/ manaus/arquivos anais/recife/politica_paulo_marcio_cruz. pdf. Acesso em: 02 mai. 2013.
DAHLBERG, L. Democracy via Cyberspace: Examining the Rhetorics and Practices of Three Prominent Camps. New Media \&Society. N. 3, 2001, p. 187-207.

DALTON, J.R. Democratic Challenges, Democratic Choices: The Erosion of Political Support in Advanced Industrial Democracies. Oxford: Oxford University Press, 2004.

FOX, R. Newstrack. Communications of the ACM. Vol. 8 N. 38, p. 11-12.

FUCHS, C. MOSCO, V. Marx is Back The Importance of Marxist Theory and Research for Critical Communication Studies. TripleC -Open Access Journal for a Global Sustainable Information Society! Vol. 10 N. 2. 2012, p. 127-632. Disponível em: http://www.triple.at/index.php/ tripleC/article/view/421. Acesso em: 23 jan.2014.

GARCIA,T.B. A democracia na era do governo eletrônico. Disponível em: http://www.egov.ufsc.br/portal/sites/default/ files/anexos/29552-29568-1-PB.pdf. Acesso em: 19 nov. 2014.

GIACOBBO SCAVO, D. BEZERRA, E. M. A crise da democracia liberal e o os novos movimentos democráticos. In: II Simpósio Nacional sobre Democracia e Desigualdades, 2014, Brasília. Anais. Disponível em: http://www. sndd 2014.eventos.dype.com.br/arquivo/download?ID_ ARQUIVO=4151. Acesso em: 19 nov. 2014.

GOMES, W. (Org.); MAIA, R.C.M. (Org.); MARQUES, F. P. J. (Org.). Internet e participação política no Brasil. 1. ed. Porto Alegre: Sulina, 2011.

GOMES, W. FERNANDES, B. REIS, L. SILVA, T. Politics 2.0: a campanha on-line de Barack Obama em 2008. Rev. Sociololgia e Política, Curitiba, v. 17, n. 34, p. 29-43, Out. 2009.

HACKER, K. VAN DIJK, J. (Eds.) Digital Democracy, Issues of Theory and Practice. London, Thousand Oaks, New Delhi: Sage, 2000.

HAGGEN, M. A typology of electronic democracy, 1997. Disponível em: http://www.uni-giessen. de/fb03/vinci/ labore/netz/hag_en.htm. Acesso: 15 ago.2014.

HOHLFELDT, A. Hipóteses contemporâneas de pesquisa em Comunicação. In: ; MARTINO, L.C.; FRANÇA, V. V. (orgs). Teorias da Comunicação: conceitos, escolas e tendências. Petrópolis: Vozes, 2001.

JENNINGS; M.K, ZEITNER, V. Internet Use and Civic Engagement: A Longitudinal Analysis. In: Oxford Journals Social Sciences Public Opinion Quarterly, Vol. 67, N. 3, Oxford, p. 311-334

KACZMARCZYK, Andrzej. Cybedemocracy: paradigm in the 21 St Century. Toronto: The Key Publishing House, 2010 . 
KUMAR, D. Mídia, cultura e sociedade: a relevância do método dialético de Marx. Revista Sinal de Menos, Ano 1, n³, 2009, p.154-169. Disponível em: https:// dl.dropboxusercontent.com/u/65249844/KUMAR_Deepa Midia_cultura_e_sociedade.pdf. Acesso em : 12 fev. 2014.

LEVY, P. Pela Ciberdemocracia. In: MORAES, Denis (org.) Por uma outra comunicação. Record: Rio de Janeiro, 2005.

MARQUES, L. Democracia radical e democracia participativa. Educação e Sociedade. Campinas, Vol. 29, N. 102, p. 55-78, jan./abr. 2008.

MOSSBERGER, K. TOLBERT, C. McNEAL, R. Digital citizenship: the internet, society and participation. MIT Press: Cambridge, 2008.

OGDEN, M. R. Politics in a Parallel Universe. Is there a future for Cyberdemocracy? Futures, N. 26, 1994, p. 713729.

OWEN, A. L., VIDERAS, J., WILLEMSEN, C. Democracy, Participation, and Life Satisfaction, Social Science, Quarterly, Vol. 89, Issue 4, 2008, p. 987-1005.

POSTER, M. Cyberdemocracy: Internet and the Public Sphere. Ms., University of California, Irvine, 1995. Disponível em: http://www.hnet.uci.edu/mposter/ writings/ democ.html. Acesso em: 19 nov.2014.

PUTNAM, R. Bowling Alone: The Collapse and Revival of American Community. New York: Simon \& Schuster, 2000 .

RÜDGER, F. Introdução às Teorias da Cibercultura. Porto Alegre: Sulina, 2007.

SHENK, D. Data Smog: Surviving the information glut. São Francisco: HarperCollins, 1997.

SNIDER, J. H. (1994): Democracy On-Line. Tomorrow's Electronic Electorate. The Futurist. September/October, p. 15-19.

TSAGAROUSIANOU, Roza. TAMBINI. Eletronic democracy and the civic networking movement in context. In: TSAGAROUSIANOU, Roza. (org.). Cyberdemocracy: technology, cities and civic networks. London: Routlege, 1998.

WELLMAN, B. Studying Internet througt the ages. In: BURNET, R. CONSALVO, M. ESS, C. Handbook of Internet Studies.Oxford: WileyBlackwell, 2011.

Recebido em: 19-11-2014 Aceito em: 05-02-2015 